\title{
PENERAPAN MEDIA AJAR DIGITAL BERBASIS 4C ( COMMUNICATION, COLLABORATION, CRITICAL THINKING AND PROBLEM SOLVING, DAN CREATIVITY AND INNOVATION) DALAM MENGHADAPI REVOLUSI INDUSTRI 4.0 DI KALANGAN GURU YAYASAN MANDIRI BERSEMI
}

\section{THE IMPLEMENTATION OF 4CS BASED DIGITAL INSTRUCTIONAL MEDIA IN FACING INDUSTRIAL REVOLUTION 4.0 AMONG TEACHERS AT YAYASAN MANDIRI BERSEMI}

\author{
R Sugiarni 1a , N Kurniawati ${ }^{1}$ \\ ${ }^{1}$ Fakultas Keguruan dan Ilmu Pendidikan Universitas Suryakencana, Jalan Pasir Gede Raya \\ a Korespondensi:Rani Sugiarni; E-mail: ranisugiarni@gmail.com \\ (Diterima: 16-04-2019; Ditelaah: 17-04-2019; Disetujui: 08-06-2019)
}

\begin{abstract}
Industrial revolution 4.0 demAnds significant And rapid changing in various aspects including education. Learning model 4.0 itself does not only require technology involvement but also students' engagement in the learning process. This demAnd is not easy to be fulfilled by the teachers, since at the end students are expected to adhere the $21^{\text {st }}$ century soft skills known as 4C (Communication, Collaboration, Critical Thinking And Problem Solving, dan Creativity And Innovation). This community service is aimed at improving the learning quality based on the 4Cs by implementing digital instructional media to embrace the industrial revolution 4.0 among the teachers in an Islamic boarding school. It involves Yayasan Pendidikan Mandiri Bersemi with its 25 teachers who are mostly categorized as Y generation. The steps included the preparation, implementation, And evaluation. Based on the study, it can be concluded that the teachers at Yayasan Pendidikan Mandiri Bersemi have been able to integrate digital media for teaching in their lesson plan And classroom activities. Keywords: Digital Instructional Media, Industrial Revolution 4, 4Cs.
\end{abstract}

\begin{abstract}
ABSTRAK
Revolusi industri 4.0 menuntut perubahan yang amat cepat dan signifikan di berbagai bidang termasuk pendidikan. Model pembelajaran 4.0 itu sendiri adalah pembelajaran yang tidak semata-mata melibatkan teknologi di dalamnya. Tapi lebih pada mengubah paradigma bahwa siswa bukanlah objek pasif yang harus, mampu menggunakan teknologi saja. Tuntutan ini tentunya bukan hal yang mudah untuk dipenuhi oleh guru. Proses pembelajaran saat ini diharapkan mampu membentuk siswa yang memiliki softskill untuk menghadapi abad 21 yang dikenal dengan 4C (Communication, Collaboration, Critical Thinking And Problem Solving, dan Creativity And Innovation). PKM ini bertujuan untuk meningkatkan kualitas pembelajaran berbasis 4C melalui penerapan media ajar digital dalam menghadapi revolusi industri 4.0 di kalangan guru pesantren. Mitra dari PKM ini adalah Yayasan Pendidikan Mandiri Bersemi. Tercatat 25 orang guru pada sekolah mitra yang berusia usia cukup muda dengan latar belakang Pendidikan Sarjana S1. Masalah yang dihadapi mitra adalah kurangnya pelatihan mengenai media ajar digital dan kurangnya kreativitas guru dalam hal teknik pengajaran. Tahapan dalam kegiatan ini peersiapan, pelaksanaan dan evaluasi. Berdasarkan pelaksanaan kegiaan ini dapat disimpulkan yakni sosialisasi penerapan media ajar digial sudah dilaksanakan dikalangan guru Yayasan Mandiri
\end{abstract}


Bersemi, para guru sudah bisa merancang rencana pelaksanaan pembelajaran dengan menggunakan media ajar digital dan sebagian guru sudah mempraktekan media ajar digital dikelas.

Kata kunci: Media ajar digital, revolusi industri 4, 4C.

Sugiarni, I., \& , Kurniawati, N., (2019). Penerapan Media Ajar Digital Berbasis 4C (Communication, Collaboration, Critical Thinking And Problem Solving, Dan Creativity Innovation) Dalam Menghadapi Revolusi Industri 4.0 Di Kalangan Guru Yayasan Mandiri Bersemi. Jurnal Qardhul Hasan; Media Pengabdian kepada Masyarakat, 5(2), 83-89.

\section{PENDAHULUAN}

Perkembangan teknologi telah mempengaruhi kehidupan setiap orang dalam berbagai aspek termasuk pendidikan. Hal ini berdampak pada wajah pendidikan yang kini telah mengalami banyak perubahan seiring dengan perkembangan teknologi ini. Media ajar, model pembelajaran, hingga profil guru dan siswa di era yang kini dikenal sebagai era revolusi industri 4.0 jauh berbeda dengan era-era sebelumnya dan semua itu tidak lepas dari pengaruh teknologi yang seakan telah menjadi nafas kehidupan manusia saat ini. Akibat dari revolusi industri ini adalah munculnya reformasi dalam pendidikan, yakni penggunanaan teknologi informasi dan komunikasi (Rosa, J. P. O. D., 2016).

Revolusi industri 4.0 menuntut perubahan yang amat cepat dan signifikan di berbagai bidang termasuk pendidikan. Para guru tanpa menghiraukan dari generasi mana mereka berasal baik itu generasi baby boomers, generasi $\mathrm{X}$, atau generasi $\mathrm{Y}$ harus mampu mengikuti arus shifting atau mereka akan tertinggal dan menyerahkan posisinya pada guru yang lebih mampu beradaptasi dengan perubahan zaman yang begitu cepat ini, dengan kata lain, change or die (Kasali, R. , 2018).

Model pembelajaran 4.0 itu sendiri adalah pembelajaran yang tidak sematamata melibatkan teknologi di dalamnya. Tapi lebih pada mengubah paradigma bahwa siswa bukanlah objek pasif yang harus mampu menggunakan teknologi saja. Tapi siswa juga harus mampu memanfaatkan teknologi tersebut sebagai sumber belajar dan juga berkolaborasi dengan siswa lain baik itu di dalam kelas maupun di luar kelas bahkan di seluruh dunia, dan peran guru lebih sebagai fasilitator, atau mediator dan bukan lagi sebagai satu-satunya sumber utama dalam proses pembelajaran.

Perkembangan teknologi dan juga gaya hidup era teknologi informasi ini menuntut guru untuk tidak sekedar mengubah media ajarnya dari kertas dan papan tulis menjadi media digital saja, tapi lebih dari itu, harus mampu membentuk siswa yang mandiri, berfikiran kritis, mampu berkomunikasi, menggunakan teknologi dan juga berkolaborasi dengan orang lain. Tuntutan ini tentunya bukan hal yang mudah untuk dipenuhi oleh guru, baik penguasaan Bahasa internasional maupun teknologi informasi dan komunikasi menjadi unsur paling penting dalam literasi agar seseorang mampu berpartisipasi dalam masyarakat informasi. Untuk membentuk yang memiliki softskill untuk menghadapi abad 21 yang dikenal dengan 4C (Communication, Collaboration, Critical Thinking And Problem Solving, danCreativity And Innovation). Sebut saja, konsep 4C sebenarnya dimiliki juga oleh model pembelajaran yang dinamai active learning. Bila active learning bisa dijabarkan dengan baik maka siswa akan dilengkapi dengan ketrampilan komunikasi, kolaborasi, berpikir kritis dan pemecahan masalah, serta berpikir kreatif dan inovatif. Hal-hal tersebut yang didorong oleh guru ketika mereka melakukan active learning. Guru sendiri harus memiliki sotfskill tersebut sebelum menularkannya pada anak didiknya. Sehingga mereka diharapkan 
mampu untuk berkompetisi di era revolusi industri 4.0 (As'ari, A.R, 2014)

Di lokasi mitra sendiri, kepala sekolah SMK Mandiri Bersemi menuturkan bahwa pelatihan media ajar terutama media ajar digital masih sangat jarang dilakukan. Sebagai sekolah yang terbilang baru, sebenarnya mitra memiliki potensi yang cukup besar untuk berkembang. Jumlah tenaga pengajar yang terdaftar disana sekitar 40 orang dengan latar belakang usia cukup muda. Latar belakang pendidikan para guru rata-rata sarjana S1. Sebenarnya sekolah memiliki fasilitas yang cukup memadai seperti computer atau laptop yang dapat digunakan oleh guru, dan beberapa ruangan kelas telah dilengkapi dengan proyektor, namun penggunaannya masih belum optimal. Para guru masih terpola untuk menggunakan media ajar konvensional, jikapun guru menggunakan media power point namun dalam kegiatan belajar mengajarnya masih sangat teacher centered, belum mengikuti pola SCL yang pada akhirnya mampu menumbuhkan keterampilan abad 21 yang seharusnya dimiliki siswa di era revolusi industri 4.0 ini.

Berdasarkan hasil observasi dan wawancara tersebut tim pengusul menyimpulkan bahwa kompetensi guru di lingkungan Yayasan Pendidikan Mandiri Bersemi dalam pemanfaatan media ajar berbasis teknologi informasi masih sangat kurang dan diperlukan upaya yang serius untuk meningkatkan kompetensi tersebut.

Dalam program PKM ini Yayasan Pendidikan Mandiri Bersemi berperan sebagai mitra. Dan berdasarkan analisis situasi dapat terindentifikasi beberapa permasalahan yang dihadapi oleh mitra, yaitu: (1) Sekolah di bawah Yayasan Mandiri Bersemi masih dalam tahap pengembangan karena masih terbilang baru; (2) Kurangnya kreativitas guru dalam menciptakan media ajar berbasis teknologi informasi; (3) Motivasi para guru untuk mengikuti pelatihan masih rendah, karena mereka sudah sangat terbebani oleh berbagai urusan administrasi sekolah, sehingga waktu mereka tersita cukup banyak. Hal ini menyebabkan para guru jarang bahkan bisa dikatakan tidak pernah mengikuti kegiatankegiatan ilmiah terkait seperti workshop ataupun pelatihan-pelatihan khususnya pelatihan media ajar digital berbasis teknologi informasi; (4) Pengetahuan dan pemahaman para guru dalam menggunakan komputer atau aplikasi dalam perancangan media ajar berbasis teknologi digital yang inovatif sangat kurang. Hal ini berdampak pada siswa kegiatan pembelajaran yang membosankan dan teacher centered; (5) Konsep keterampilan abad 21 atau 4 C belum dikenal oleh guru di Yayasan Mandiri Bersemi dan; (6) Tidak semua kelas dilengkapi dengan fasilitas yang layak untuk menjamin kegiatan belajar mengajar.

Dari permasalahan tersebut di atas tentunya harus ditemukan solusi yang tepat untuk mengatasinya dengan merujuk pada beberapa teori dan temuan penelitian terkait mengenai peningkatan kompetensi guru dalam hal penguasaan teknologi dan pemanfaataanya sebagai media ajar.

Menurut hasil penelitian (Jumali, 2014), kualifikasi pendidikan guru juga mempengaruhi kompetensi TIK guru. Terdapat beberapa faktor yang menghambat peningkatan kompetensi TIK guru, seperti: 1) guru enggan melakukan perubahan dalam melaksanakan kegiatan pembelajaran; 2) waktu guru yang tersedia untuk mempersiapkan pembelajaran yang penggunaan TIK sangat terbatas; 3) akses guru terhadap berbagai sumber informasi masih terbatas; 4) pelatihan guru di bidang pemanfaatan TIK untuk pembelajaran masih terbatas dan belum merata hingga ke derah, dan 5) dukungan teknis dan aturan pemanfaatan TIK untuk pembelajaran masih belum jelas (Siahaan, S. ,2015).

Faktor lain yang turut menghambat peningkatan kompetensi guru dalam menggunakan TIK untuk pembelajaran adalah dukungan dari sarana dan prasarana sekolah. Berdasarkan data Kementerian Pendidikan dan Kebudayaan RI (2017) menunjukkan bahwa jumlah sekolah dasar di Indonesia yang telah memiliki 
laboratorium masih sekitar 4\% dan yang memiliki perpustakaan sekitar 55\%.

Maka dari itu kegiatan pengabdian ini akan berusaha memberikan solusi yang dihadapi oleh mitra dengan mengadakan pelatihan dan berlanjut dengan membentuk forum diskusi di bawah naungan Yayasan Pendidikan Mandiri Bersemi, adapun pelatihan meliputi: (1) Pengenalan dan penggunaan beberapa media pembelajaran digital berbasis aplikasi teknologi informasi dan komunikasi; (2) Pengenalan dan penggunaan beberapa perangkat lunak dan aplikasi, diantaranya QR Code, Kahoot, Powtoon, Mimind, dan Canva; (3) Pengenalan konsep 4C; (4) Pengenalan model belajar yang dapat menumbuhkan 4C dan; (5) Pengintegrasian media ajar digital dan model belajar yang dapat menumbuhkan 4C.

\section{MATERI DAN METODE}

Pelaksanaan kegiatan pengabdian ini bertempat di Yayasan Pendidikan Mandiri Bersemi. Tercatat 25 orang guru pada Sekolah Menengah Pertama dan Sekolah Menengah Kejuruan mitra yang berusia usia cukup muda dengan latar belakang Pendidikan Sarjana S1.

Metode yang digunakan meliputi tiga tahap yakni tahapan awal yakni tahap persiapan observasi, penentuan jadwal dan penyusuanan bahan ajar dan instrumen. Tahap kedua tahap pelaknaan yakni dalam kegiatan ini pertama sosialisasi dengan jenis kegiatan workshop penerapan media ajar berbasis digital, tahap kedua workshop merancamg RPP (Rencana Pelaksanaan Pembelajaran) dengan mengintegrasikan media digital, Tahap ketiga open class dan tahap ketiga evaluasi.

\section{HASIL DAN PEMBAHASAN}

Hasil yang diperoleh dari pelaksanaan pengabdian di Yayasan Mandiri Bersemi dari setiap tahapan yang dilaksanakan adalah sebagai berikut:

\section{Tahap awal}

Pada tahap awal pengabdian tim berkoordinasi jadwal pengabdian dengan pihak yayasan Mandiri bersemi. Kemudian tim pelaksana mempersiapkan bahan ajar digital berbasis $4 \mathrm{c}$ dan instrumen angket.

\section{Tahap pelaksanaan}

Pada tahap awal pelaksanaan pengabdian tim pelaksana melaknakan sosialisasi program penerapan bahan ajar berbasis digital serta rencana tahapan program kedepannya berserta target luaran yang harus guru capai. Sosialisasi dilaksanakan dalam bentuk workshop yang dilaksanakan pada tanggal 5 April 2019 dengan judul Workshop Media Ajar Digital di Kalalangan Guru Yayasan Mandiri Bersemi.

Gambar 1. Workshop Media Ajar Digital.

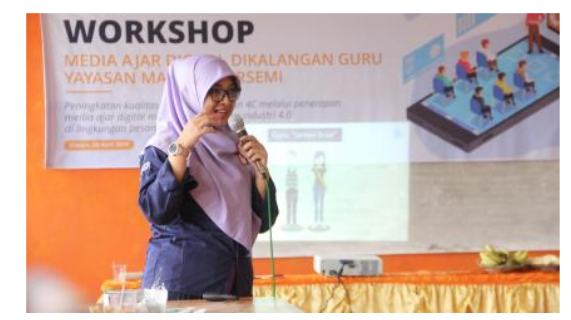

Materi yang disajikan berupa pengenalan dan praktek media ajar digital yaitu QR Code, Kahoot, Powtoon, Mimind, dan Canva.

Gambar 2. Praktek penggunaan Media Ajar Digital.

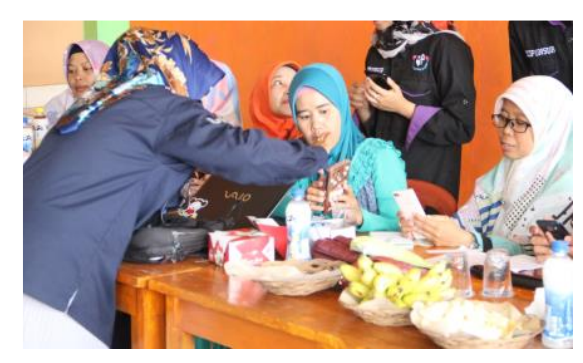

Setelah para guru yayasan Mandiri Bersemi sudah mengenal dan memahami media ajar digital. Kemudian tahap dua workshop dilanjutkan dengan merancamg pelakasanaan pembelajaran berbasis media ajar digital pada tanggal 13 April 2019. Para guru secara berkelompok menentukan media digital yang cocok dengan tercapainya tujuan pembelajaran pada rencana pelaksana pembelajaran. 


\section{Gambar 3. Diskusi Kelompok}

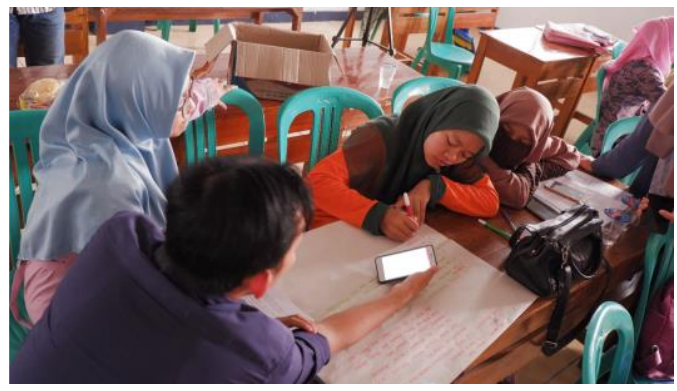

Setelah para guru merancang rencana pelaksana pembelajaran kemudian masingmasing kelompok mempresentasikan hasil diskusi di depan kelas seperti gambar berikut:

Gambar 4. Presentasi Hasil Diskusi

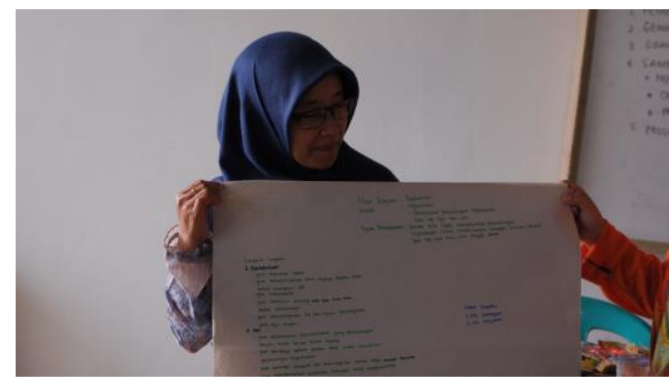

Masing-masing guru mendapatkan proyek untuk membuat rencana pelaksanaan pembelajaran menggunkan media jaringan digital yang sudah diberikan. Pengumpulan rencana pelaksana pembelajaran dikumpulakan dengan link padled sebagai berikut:

Gambar 5. RPP Media Ajar Digital

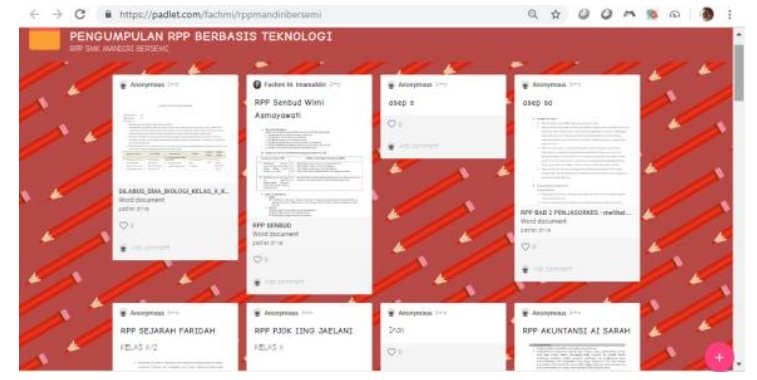

Tahap ketiga pelaksanaan open class yakni para guru mempraktekan rencana pelaksanaan pembelajaran pada siswa-siswi dikelas. Pelaksanaan open class diambil dua orang guru terpilih dari kumpulan rencana pelaksanaan pembelajaran yang terbaik dari kalangan guru yayasan Mandiri Bersemi. Open class pertama dilaksanakan pada tanggal 16 April 2019 mata pelajaran matematika dengan menggunkan bahan ajar digital yang dipilih yakni QR Code yang dipakai guru untuk lembar kerja siswa dan Kahoot diakhiri pembelajaran untuk evaluasi akir pembelajaran matematika.

Gambar 6. Aktivitas Siswa Menggunkan Media Ajar Digital.

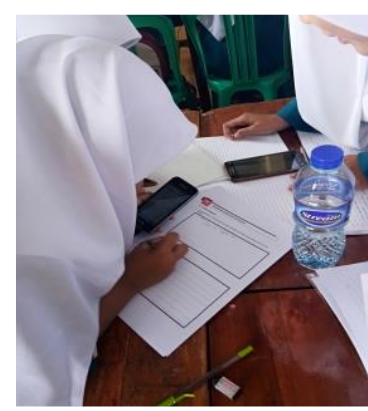

Open class kedua dilaksanakan pada tanggal 18 April 2019 mata pelajaran bahasa Inggris dengan menggunkan media ajar digital yakni mimind dan whatsap. Tahap-tahap pelaksanaan penerapan media ajar digital dikalsanakan dengan baik dengan kalangan guru yayasan Mandiri Bersemi.

\section{Tahap evaluasi}

Pada tahap evaluasi yakni tahap akhir pelaksanaan penrapan media ajar digital. Kegiatan evaluasi ini dalam bentuk Seminar dan Hasil Penerapan Media Ajar digital dikalangan guru Yayasan Mandiri Bersemi. Pada seminar dan hasil ini dipaparkan selama pelaksanaan berlangsung melalui video dan presentasi hasil evalusi penerapan media ajar dikelas. Respon siswa-siswi selama penggunaan media ajar digital positif dengan penggunaan $Q R$ Code dan Kahoot serta Mimind.

Gambar 7. Seminar dan Hasil

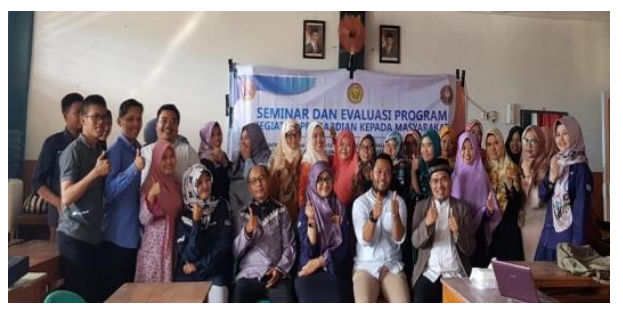

Pada hasil seminar dipaparkan para guru kesulitan mereka dalam penggunaan media ajar digital yakni kurangnya sarana dan prasarana yang memadai seperti contohnya 
tidak semua siswa memiliki telepon selular Android dan jaringan internet yang kurang terjangkau di kelas. Namun kesulitan dalam penggunaan media ajar digital ini tidak menurunkan semangat para guru Yayasan Mandiri Bersemi. Para guru diharapkan mempunyai keterampilan $4 \mathrm{C}$ yang salah satunya menuntut mereka untuk kratif dalam menghadapi situasi dan kondisi yang ada di kelas dengan mamanfaatkan sarana dan prasarana yang ada di kelas dan di sekolah dengan mengikuti tantangan abad 21 yakni penggunaan teknologi selama proses pembelajaran dikelas.

\section{KESIMPULAN}

\section{Kesimpulan}

Berdasarkan pelaksanaan kegiaan ini dapat disimpulkan sosialisasi penerapan media ajar digial sudah dilaksanakan dikalangan guru Yayasan Mandiri Bersemi, para guru sudah mampu merancang rencana pelaksanaan pembelajaran dengan menggunakan media ajar digital dan sebagian guru sudah mempraktekan media ajar digital di kelas. Kegiatan ini bisa berjalan lancar atas izin dari yayasan Mandiri bersemi yang mendukung penuh selama kegiatan berlangsung dilapangan. Sedangkan faktor penghambat dalam kegiatan ini adalah jadwal para guru yang bersamaan dengan program sekolah sehingga para guru kurang maksimal mengikuti kegiatan ini. Dari kegiatan ini yang dapat disarankan bagi petani di Desa Sukamantri Kecamatan Tamansari ini perlu adanya pembinaan dalam pengetahuan dan keterampilan lebih lanjut untuk menciptakan kemandirian para petani, perlu dibentuknya kelompok-kelompok kecil agar tercipta untuk saling bertemu serta bertukarpikiran dan pengalaman diantara para petani. Upaya ini akan sangat membantu dalam penyelesaian permasalahan teutama bagi mereka yang mengalami masalah yang sama.

\section{Saran}

Saran kegiatan ini agar para guru dapat mengaplikasikan bahan ajar digital pada materi lain dan menyesuaikan dengan tujuan pembelajaran, keberlanjutan program kegiatan ini dengan mendampingi guru mengaplikasikan media ajar digital di kelas dan penerapan media ajar digital bisa dilaksanakan dengan kalangan guru yang lebih luas lagi.

\section{UCAPAN TERIMA KASIH}

Tim mengucapkan terimakasih kepada semua pihak yang ikut membantu dalam pelaksanaan penelitian dan DRPMRistekdikti yang telah memberikan dukungan materi sehingga bisa terlaksana pengabdian ini.

\section{DAFTAR PUSTAKA}

As'ari, A.R. 2014. Ideas for Developing Critical Thinking at Primary School. Paper presented at an International Seminar on Adrressing Higher Order Thinking: Critical Thinking Issues in Primary Education. Makasar, April 12 - 13, 2014: Universitas Islam Muhammadiyah Makasar

Jumali. (2014). Profesionalisme GuruGuru Madrasah Ibtidaiyah Muhammadiyah Ceper. Jurnal Pendidikan Ilmu Sosial, 24(2), 45-52. Retrieved from journals.ums.ac.id/

index.php/jpis/article/download/679 $/ 413$

Kasali, R. (2018) The Great Shifting. Jakarta: Gramedia.

Rosa, J. P. O. D. (2016). Experiences, perceptions And attitudes on ICT Integration: A case study among novice And experienced language teachers in the Philippines. International Journal of Education And Development using Information And Communication Technology, 12(3), 37. 
Siahaan, S. (2015). Pemanfaatan Teknologi Informasi dan Komunikasi dalam Pembelajaran: Peluang, Tantangan, Dan Harapan. Jurnal Teknodik, 19(3), 321-332.

Tim Dapodikbud Jendela Pendidikan dan Kebudayaan. (2017). Persentase Guru Kualifikasi (Minimal S1). Retrieved September 29, 2017, from http://jendela.data.kemdikbud.go.id/j e ndela/\# 